\title{
UM PROJETO PARA A NAÇÃO. TENSÕES E INTENÇÕES POLIITICAS NAS "PROVÍNCIAS DO NORTE" (1817-1824)
}

Luiz Geraldo Silva

Universidade Federal do Paraná

\section{Resumo}

O presente artigo defende a idéia conforme a qual as discussões travadas nas províncias do Norte, entre 1820 e 1824, não acenaram para a constituição de estados ou nações independentes. Antes, elaborou-se ali, ao longo daqueles anos, um projeto para o conjunto do que outrora fora a América portuguesa, ou um projeto para nação brasileira. Assim, o que estava em questão não era a secessão do Império, mas a defesa do pacto constitucional e federativo que deveria garantir a unidade do Império, “do Amazonas ao Prata”.

\section{Pallavras-chaves}

Pernambuco • projetos políticos • nação • Império do Brasil.

\section{Abstract}

This article suggests that some political groups of provinces of North of Portuguese America, mostly from Pernambuco, didn't wanted to establish independent nations or states in those parts of Brazil from 1820 to 1824. In fact, there was a political project among the local political groups about the Brazilian nation, and there the principal subject was not the secession from the Empire of Brazil. For them the federal and constitutional principles were the guarantees of the Empire unity, "from Amazonas to Prata”.

\section{Keywords}

Pernambuco $\bullet$ political projects $\bullet$ nation $\bullet$ Brazil Empire. 
Em Pernambuco e sua área de influência - as capitanias e, depois, províncias do Ceará, Paraíba, Rio Grande do Norte e Alagoas -, o processo de Independência apresentou trajetória peculiar. Afinal, foi naquela região que eclodira, em 1817, sob a presença da corte joanina nos trópicos, um movimento político cujo objetivo era instituir um regime que pretendia ser, ao final de contas, republicano. Neste, amplos setores da sociedade pernambucana e das demais “províncias do Norte” ensejaram uma separação radical da monarquia portuguesa, então organizada sob a forma do Reino Unido de Portugal, Brasil e Algarves. Claro está que a idéia de ruptura com o poder monárquico não surgiu repentinamente em 1817, mas trazia marcas muito antigas, enraizadas na experiência histórica daquele território. Embora todas as partes da América portuguesa possuíssem uma dupla identidade, isto é, regional e lusitana, a região aqui considerada revelava faceta particular. A representação mental da restauração contra o domínio holandês, empreendida no século XVII, ou mesmo a guerra civil de 1710-1712 - que colocou os senhores de terra sediados em Olinda contra os privilégios dados pela Coroa aos mercadores da vila do Recife -, marcaram sobremaneira a memória e a experiência histórica local. Estes aspectos ainda possuíam um amplo poder de mobilização nas primeiras décadas do século XIX. Ademais, eles se tornaram, então, passíveis de serem reinterpretados à luz das idéias ilustradas amplamente difundidas por aqueles anos em todo mundo atlântico. ${ }^{1}$

Porém, ao contrário do que sugeriu uma historiografia regional e nativista, 1817 não significou uma antecipação da Independência do Brasil ${ }^{2}$ e muito

\footnotetext{
${ }^{1}$ Sobre o impacto do movimento político de 1817 na política regional nos anos imediatamente subseqüentes, àquele evento, ver o estudo de BERNARDES, Denis A. M. O patriotismo constitucional: Pernambuco, 1820-1822. São Paulo/Recife: Hucitec/Fapesp/Editora da UFPE, 2006, caps. 5 e 6; sobre as duplas identidades das províncias da América portuguesa, a regional e a lusitana, ver o ensaio de JANCSÓ, István \& PIMENTA, João Paulo G. Peças de um mosaico (ou apontamentos para o estudo de emergência da identidade nacional brasileira). In: MOTA, Carlos G. (org.). Viagem incompleta. A experiência brasileira (1500-2000). São Paulo: Editora Senac, 2000, p. 127-175; sobre a construção da identidade de Pernambuco entre os séculos XVII e XIX, ver MELLO, Evaldo Cabral. Rubro veio. O imaginário da restauração pernambucana. Rio de Janeiro: Topbooks, 1997.

${ }^{2}$ Uma visão da historiografia regional pode ser buscada em LIMA SOBRINHO, Barbosa. Pernambuco: da independência à Confederação do Equador. Recife: Prefeitura da Cidade do Recife, 1998, p. 24; conforme escreve Oliveira Lima, desde 1817 os pernambucanos tentavam conduzir "o barco do Estado ao porto feliz da independência com a república". LIMA, Manuel de Oliveira.
} 
menos representou, como afirmou a historiografia saquarema, ${ }^{3}$ um movimento separatista, ou uma cisão no interior de um corpo político mais ou menos consolidado. Ora, naquele momento os pernambucanos longe estavam de se enxergar em meio a uma luta entre "metrópole e colônia" e, muito menos, o Reino Unido se afigurava a uma "proto-nação brasileira". Ante tais postulados, faz-se necessário situar os termos da experiência republicana de 1817 nos quadros da crise do Antigo Regime na América, o que equivale perceber, por um lado, as formas de enfrentamento político do poder monárquico então disponíveis e, por outro, os modelos capazes de fornecer um quadro institucional que tornasse viável um governo autônomo, ainda que provisório, no interior do Reino Unido. ${ }^{4}$

Levando-se em consideração as forças políticas que participaram do movimento contra a monarquia em 1817, observa-se que o segundo momento vital desta análise é aquele subseqüente ao chamamento das Cortes Constituintes da Nação Portuguesa (1820). Embora dom João tivesse acenado com um perdão real em janeiro de 1818, alguns dos implicados no movimento de 1817 que não haviam sido sentenciados à morte ainda se achavam presos nos cárceres da Bahia em inícios da década de 1820. Foi, então, graças à Revolução do Porto e à formação da Assembléia Constituinte em Lisboa que muitos dos "patriotas" puderam retornar à província e às lides políticas. Na perspectiva, porém, da histografia saquarema, como escreve Varnhagen na década de 1870, “quando começaram a chegar da Bahia as vítimas dos acontecimentos de 1817, pois, por mais que o governador [Luís do Rego Barreto (1817-1821)] procurou atendê-

O movimento da independência. São Paulo: Melhoramentos, 1922, p. 231.

${ }^{3}$ A "historiografia saquarema" é definida por Evaldo Cabral de Mello como "a historiografia da corte fluminense e dos seus epígonos na República, para quem a história da nossa emancipação política reduz-se à da construção do Estado unitário. Nesta perspectiva apologética, a unidade do Brasil foi concebida e realizada por alguns indivíduos dotados de grande descortínio político, que tiveram a felicidade de nascer no triângulo Rio-São Paulo-Minas e a quem a pátria ficou devendo o haverem-na salvo da voracidade dos interesses provinciais, como se estes fossem por definição ilegítimos, e do gosto, digamos, ibero-americano, pela turbulência e pela agitação estéreis, como se Eusébio, Paulino ou Rodrigues Torres não fossem representantes de reivindicações tão regionais quanto às de Pernambuco, do Rio Grande do Sul ou do Pará”. Cf: MELLO, Evaldo Cabral de. Frei Caneca ou a outra Independência. In: Caneca, frei do Amor Divino. 2001. In: MELLO, Evaldo Cabral de (org.). Frei do Amor Divino Caneca. São Paulo: Editora 34, 2001, p. 16.

${ }^{4}$ Já discuti algumas dessas questões em dois ensaios anteriormente publicados: SILVA, Luiz Geraldo. "Pernambucanos, sois portugueses!” Natureza e modelos políticos das revoluções de 1817 e 1824. Almanack Braziliense. São Paulo, v. 1, 2005, p. 67-79; SILVA, Luiz Geraldo. O avesso da Independência: Pernambuco (1817-1824). In: MALERBA, Jurandir (org.). A Independência brasileira. Novas dimensões. Rio de Janeiro: Editora FGV, 2006, p. 343-384. 
los, pagando-lhes ordenados e restituindo-os a seus lugares, não se mostravam satisfeitos, e tramavam sem cessar”. Para além das interpretações centradas na figura do príncipe e da perspectiva conformada aos ditames da corte fluminense, houve, na verdade, entre 1821 e 1823, uma retomada das aspirações autonomistas, ou mesmo sua realização, após estas terem sido represadas pela feroz repressão perpetrada pelo comandante do bloqueio naval ao porto do Recife em 1817, José Ferreira Lobo, e pelo governador Luís do Rego Barreto. ${ }^{5}$

\section{II}

Como se sabe, as Cortes Constituintes, cujo chamamento se deu a partir de dezembro de 1820, permitiram a formação de governos provinciais de caráter provisório, facultando aos grupos provinciais participar diretamente da administração de suas "pátrias" - compreendidas pelos contemporâneos como local de nascimento e como territórios dotados de alguns princípios de identidade. Contudo, a adesão de Pernambuco ao constitucionalismo - que se seguiu à de Pará ( $1^{\circ}$ de janeiro de 1821) e Bahia (10 de fevereiro) - não se fez sem contradições, violências ou derramamento de sangue. Ali, o governador Luís do Rego Barreto procurou controlar os termos da adesão e impedir o acesso dos grupos políticos locais ao poder da província. ${ }^{6}$

Em carta de 20 de maio de 1821, Barreto informou a dom João que, ao saber de seu juramento à "Constituição da Monarquia", dera "todas as ordens necessárias para as eleições dos Deputados desta província para a representação em Cortes, par a par com os outros Representantes da Nação”. Atalhava assim a ação de "alguns facciosos" que espalhavam "doutrinas absurdas, mas que podiam achar partido no povo". Tais facciosos, ainda conforme Barreto,

... julgaram ser-lhes lícito empreenderem mudanças de Governo, e de administração, feitas tumultuosamente e por homens obscuros e ferozes, que em nada punham a mira, senão em seu próprio interesse, na queda

\footnotetext{
${ }^{5}$ Cf: VARNHAGEN, Francisco Adolfo. História da independência do Brasil. Revista do Instituto Histórico e Geográfico Brasileiro. Rio de Janeiro: IHGB, tomo LXXIX, 1916, [1876], p. 398 (separata).

${ }^{6}$ Cf: BERBEL, Márcia Regina. A nação como artefato. Deputados do Brasil nas cortes portuguesas (1821-1822). São Paulo: Hucitec/Fapesp, 1999; JANCSÓ, István \& PIMENTA, João Paulo G. Peças de um mosaico..., p. 127-130; BERNARDES, Denis A. M. O patriotismo constitucional..., 2000, p. 380-397.
} 
de pessoas que lhes eram odiosas, e em uma celebridade louca, triste remedo do arrojo heróico dos nossos Restauradores em bem diversas circunstâncias. ${ }^{7}$

Ademais, o governador afirmou, por um lado, que já havia em Pernambuco grupos políticos formados sob o intuito de compor uma Junta de Governo e que, por outro lado, discutia-se abertamente a nova configuração política da monarquia, posto que

... alguns demagogos levantaram depois do dia 26 de março uma voz de independência, não propriamente de uma separação absoluta, mas o seu fito era, a meu parecer, um Governo Federal, deixando cada Capitania governar-se por si, e por o que eles chamavam Patrícios; este partido ia ganhando prosélitos ... Coroavam-se estes fins com as aparentes pretensões de uma Junta Provisional, eleita pelo povo, mas corriam pelas mãos dos prosélitos do novo sistema listas dos que haviam de ser nomeados. ${ }^{8}$

Como se percebe, a resistência de Barreto ao novo estado de coisas foi enorme e, ao mesmo tempo, a pressão dos grupos locais no sentido de controlar o poder político na província consubstanciava-se na tomada de decisões de caráter prático e em discussões de formas institucionais. Desse modo, somente por meio de uma guerra civil, iniciada, como sempre, ao norte do Recife, e da criação de uma Junta paralela ao governo de Barreto, a qual fora instalada na cidade de Goiana, é que os grupos locais conseguiram isolar o governador no Recife e em Olinda e forçar sua deposição. ${ }^{9}$

Porém, ao contrário do que esses fatos possam sugerir, faz-se necessário salientar que o período do constitucionalismo luso-brasileiro também não

\footnotetext{
${ }^{7}$ Cf: Carta do governador da capitania de Pernambuco, Luís do Rego Barreto, ao rei d. João VI sobre ter tomado conhecimento do juramento à Constituição e informando as medidas tomadas para a eleição dos deputados da dita capitania que seguirão viagem ao Reino; as dificuldades de se proceder as eleições devido as distâncias das comarcas e os receios do povo; e informando ter reprimido todas as idéias propagadas nesta capitania acerca da instalação de um governo federal. A.H.U - Pernambuco, cx. 281, doc. 19148. Recife, 20 de maio de 1821.

${ }^{8}$ Cf: Idem, ibidem.

${ }^{9}$ Cf: BERBEL, Márcia Regina. A nação como artefato..., p. 57-65; BERNARDES, Denis A. M. Pernambuco e sua área de influência: um território em transformação (1780-1824). In: JANCSÓ, István (Org.). Independência: história e historiografia. São Paulo: Hucitec/Fapesp, 2005, p. 379-409.
} 
representou uma antecipação da Independência política da América portuguesa. Antes, ele significou um momento de aproximação entre a colônia e sua metrópole, ou entre cada província e a monarquia portuguesa. Este aspecto é claramente observado nos vários documentos elaborados pelas Juntas de Governo das províncias e mesmo na carta do governador Luís do Rego Barreto antes mencionada: nela se fala da pretensão dos grupos locais a uma "independência", mas "não propriamente de uma separação absoluta". O objetivo era a autonomia provincial, politicamente viável dentro de um regime federativo, ou “um Governo Federal, deixando cada Capitania governar-se por si”. É falsa, pois, a afirmação segundo a qual a primeira Junta constitucional de Pernambuco, presidida pelo comerciante de grosso trato Gervásio Pires Ferreira (26 de outubro de 1821 a 16 de setembro de 1822), como escreve Oliveira Lima, “estava deslizando rapidamente para a anarquia sob pretexto de conquistar a liberdade”. O que esta almejava, acima de tudo, era administrar a província nos marcos da monarquia constitucional o mais amplamente possível, isto é, com forte acento na autonomia provincial. Até então, em nenhum momento se havia pleiteado uma ruptura local, ou mesmo regional, com o Reino Unido. Tal ruptura, paradoxalmente, só aparece no horizonte após fevereiro de 1822, mas por sugestão do príncipe regente e dos próceres do Rio de Janeiro, Minas e São Paulo. ${ }^{10}$

Assim, curiosamente, antigos partidários da República de Pernambuco haviam-se conformado com os termos propostos pelas Cortes, de uma monarquia constitucional com sede em Lisboa. Afinal, manejar as contas da província, aplicar suas rendas como bem quisessem, controlar as forças armadas, projetar reformas educacionais e introduzir mecanismos diferenciados de governo político constituíam aspectos fundamentais para os grupos políticos locais. ${ }^{11}$ Em suma, aspiravam, sobretudo, à autonomia provincial, como já se disse aqui, a qual se tornara possível graças ao constitucionalismo luso-brasileiro e à disseminação, por estes anos, do princípio federativo. Profissionais liberais, padres, representantes do comércio de grosso trato e produtores ligados ao novo e dinâmico artigo de exportação da província, o algodão, contavam entre aqueles homens. Eles tinham como base territorial o Recife e o norte da província, incluindo a populosa vila de Goiana. Alguns senhores de engenho, sobretudo residentes na Zona da Mata Norte, também perfilavam com aqueles, mas a tendência da

\footnotetext{
${ }^{10}$ Cf: LIMA, Manuel de Oliveira. O movimento da independência..., p. 236.

${ }^{11}$ Cf: BERNARDES, Denis A. M. O patriotismo constitucional..., cap. 7.
} 
açucarocracia será a de ruptura paulatina, ao longo da fase constitucional, com o federalismo provincial. ${ }^{12}$

Com efeito, é necessário destacar que a possibilidade de governar a província criava diferenças importantes entre antigos inimigos da monarquia bragantina, outrora ombreados em 1817. Ademais, as soluções adotadas nos momentos decisivos do conflito contra o Reino Unido haviam gerado tensões profundas entre seus diferentes grupos políticos. Nessa direção, a incorporação de escravos e de homens livres de cor entre partidários e combatentes da ruptura republicana constituía, para alguns, aspecto temerário e perigoso, um expediente de triste memória. É nesse quadro, pois, que as forças políticas oriundas daquele movimento tomam direções diversas na época do constitucionalismo luso-brasileiro. ${ }^{13}$

Sugere-se aqui que este divórcio entre antigos aliados constitui aspecto central para o entendimento do que vem a ser, depois, o processo de independência em Pernambuco. Freqüentemente, põe-se ênfase demasiada nas idéias e práticas do grupo federalista, isolando-o de uma configuração relacional da qual faziam parte os demais grupos políticos - notadamente aqueles partidários da centralização. Este aspecto, aliás, pode ser atestado pelas inúmeras análises produzidas em torno do pensamento de frei Caneca e de outros militantes "patriotas” e radicais. ${ }^{14}$ Pouco se discute, inversamente, o lado adesista da província, constituído pelos irmãos Cavalcanti, pelos irmãos Gama e pelo morgado do Cabo, Francisco Paes Barreto. É preciso, pois, não olhar as posições do grupo político que aceitou os termos do projeto do Rio de Janeiro com estranhamento apenas porque Pernambuco e as demais “províncias do Norte” constituíam uma "região de tradição liberal e contestatória". ${ }^{15}$ Antes, faz-se necessário sublinhar que havia ali bases tão sólidas para a contestação como para a franca aceitação da causa imperial - a qual, como em poucas províncias do Império, fora ali tão acintosamente vitoriosa.

\footnotetext{
${ }^{12}$ Cf: MELLO, Evaldo Cabral de. A outra independência. O federalismo pernambucano de 1817 a 1824. São Paulo: Editora 34, 2004.

${ }^{13}$ Cf: CARVALHO, Marcus J. M. de. Cavalcantis e cavalgados: a formação das alianças políticas em Pernambuco, 1817-1824. Revista Brasileira de História, vol.18, n 36, 1998, p. 331-366.

${ }^{14}$ Cf: LYRA, Maria de Lourdes Viana. 1998. Pátria do cidadão: a concepção de pátria/nação em frei Caneca. Revista Brasileira de História, vol. 18, nº 36.

${ }^{15}$ Cf: MELLO, Evaldo Cabral de. Frei Caneca ou a outra Independência. In: Caneca, frei do Amor Divino. 2001. In: MELLO, Evaldo Cabral de (org.). Frei do Amor Divino Caneca. São Paulo: Editora 34. 2001, p. 35.
} 
A base da ruptura radical entre os grupos políticos de Pernambuco, a qual daí por diante porá em campos opostos federalistas e centralizadores, será o chamado projeto do Rio de Janeiro. Este aparece no horizonte num momento em que as províncias da América portuguesa gozavam da mais ampla autonomia - prerrogativa, aliás, sequer imaginada nos tempos dos governadores e capitães generais enviados por Lisboa e, depois de 1808, pelo Rio de Janeiro. É nessa linha que se entende porque a primeira Junta de Governo Provisório de Pernambuco, mas também as de outras "províncias do Norte”, como a da Paraíba, custassem a reconhecer a autoridade do príncipe regente e a pertinência daquilo que se passou a denominar de "independência". Como notou Bernardes, soava desrespeitoso para os governantes locais o rompimento do pacto penosamente construído com as Cortes Constituintes e, sobretudo, com dom João VI, bem como parecia difícil abrir mão da autonomia provincial recentemente adquirida. Assim sendo, os áulicos do príncipe acabam por perpetrar golpe de Estado que levou à destituição da primeira Junta Provisória de Pernambuco, presidida por Pires Ferreira, e à eleição da chamada Junta dos Matutos (outubro de 1822 a dezembro de 1823), a qual entronara os senhores de engenho da Mata Sul no poder da província. Desse modo, derrubava-se o governo constituído de modo a pavimentar os caminhos tortuosos da independência em Pernambuco. ${ }^{16}$

\section{III}

Consumada a independência e tornando-se esta sabida pelo conjunto das províncias em fins de 1822, restou, aos federalistas pernambucanos, se conformarem com o chamado "projeto do Rio de Janeiro". Isso ocorreu não por traição dos princípios antes defendidos, como afirmaram alguns historiadores, mas por três razões básicas que inviabilizaram a defesa da autonomia provincial sob o Reino Unido. Em primeiro lugar, os trabalhos nas Cortes Constituintes fracassaram no sentido de salvaguardar os direitos federativos das províncias do Brasil. Este duro golpe deu ensejo à entrada em cena de projetos políticos acalentados pela bancada paulista ao tempo das Cortes Constituintes. Tais projetos tenderam a se materializar na confrontação entre o príncipe e Lisboa, inclusive com o chamado de uma Constituinte no Brasil em junho de $1822 .{ }^{17}$ Em segundo lugar, observou-se que, internamente à província, amplos setores das camadas

\footnotetext{
${ }^{16}$ Cf: BERNARDES, Denis A. M. Pernambuco e sua área de influência..., p. 379-409.

${ }^{17}$ Cf: BERBEL, Márcia Regina. A nação como artefato..., p. 193-194.
} 
populares - notadamente os militares "pretos" e "pardos" -, viram na criação do corpo político independente de Portugal motivo de júbilo, apoiando-o enfaticamente. Tais setores, amplamente presentes em 1817, tendiam, agora, a desconfiar daqueles que não aceitassem a ruptura definitiva com Portugal. Não por acaso tiveram papel destacado na conflagração que levou os Matutos ao poder em outubro de 1822. Desse modo, a sociedade local estava dividida não apenas entre suas elites políticas e econômicas, mas também entre o povo comum. ${ }^{18}$

Finalmente, e em terceiro lugar, a aceitação da independência por parte dos federalistas decorreu principalmente do fato de o príncipe acenar, naquele momento, com uma proposta constitucional. Ora, recorde-se mais uma vez que esta equivalia conferir aos grupos locais o direito de administrar rendas, controlar força militar e, sobretudo, exercer a governabilidade dos povos. Conferir tais predicados a todos os grupos políticos locais equivalia desbaratar todo e qualquer despotismo. Ademais, se os princípios federalistas puderam ser implementados no interior da velha ordem, ao longo da fase do constitucionalismo luso-brasileiro, por que não o seriam neste novo momento, marcado pela ruptura definitiva, no dizer de frei Caneca, com o "velho e estonteado Tejo"?. O símbolo dessa adesão dos federalistas ao "projeto do Rio de Janeiro", e o fim de suas resistências a ele, materializou-se no Sermão da Aclamação, pregado pelo carmelita na matriz do Corpo Santo a 8 de dezembro de 1822. Neste aduzia Caneca que fora dom Pedro “aquele príncipe justo, magnânimo, incomparável, que tocado dos nossos males passados e das injustiças presentes do Congresso lisbonense a nosso respeito" proclamara "aquele último termo político, que nos dá liberdade, afiança a reintegração de nossos direitos postergados, assegura nossa felicidade e preconiza a nossa glória". ${ }^{19}$

Essa adesão à independência, como se viu, ocorria num momento em que sua facção não exercia o controle político da província. Como também já se observou, em setembro de 1822, Bonifácio havia arquitetado a derrubada da Junta gervasista por meio de um enviado seu a Pernambuco, Antônio de Meneses Vasconcelos de Drummond..$^{20}$ A resistência da Junta em aceitar os termos do

\footnotetext{
${ }^{18}$ Cf: SILVA, Luiz Geraldo. Negros patriotas. Raça e identidade social na formação do Estadonação (Pernambuco, 1770-1830). In: JANCSÓ, István (org.). Brasil: formação do Estado e da nação. São Paulo/Injuí: Hucitec/Unijuí, 2003, p. 497-520.

${ }^{19}$ Cf: MELLO, Evaldo Cabral de (org.). Frei do Amor Divino Caneca. São Paulo: Editora 34, 2001, p. 104.

${ }^{20}$ Cf: Anotações de A. M. V. de Drummond à sua biografia. Anais da Biblioteca Nacional do Rio
} 
projeto do Rio de Janeiro, notadamente o decreto de 16 de fevereiro relativo à criação do Conselho de Procuradores das Províncias, fora o motivo do golpe que a derrubara. Assim sendo, subia ao poder, em outubro de 1822, a Junta dos Matutos, tendo por presidente Afonso de Albuquerque Maranhão e por membros Francisco Paes Barreto, Francisco de Paula Cavalcanti e Albuquerque, Manoel Inácio Bezerra de Melo e José Marinho Falcão Padilha. Tratava-se de grupo local apegado aos antigos padrões de condução da política econômica do Antigo Regime, mormente vinculados à produção açucareira e baseados na Zona da Mata Sul da província. Estes vão encontrar alento no projeto de José Bonifácio e de outros áulicos do primeiro imperador, como demonstra seu entusiasmo, externado em 23 de novembro de 1822, pela aclamação de dom Pedro. Neste dia, a Junta oficia ao imperador informando-o de que os "habitantes de Pernambuco" revelavam ser "os primeiros que consideraram como um dever dos Brasileiros (...) a necessidade de aclamar a Vossa Majestade Imperial por Seu Legítimo Monarca Constitucional, contido então em seus ardentes desejos pelo amor da Ordem e da legalidade" ${ }^{21}$ Ainda nesse momento, federalistas e centralizadores construíam diferentes interpretações da independência, mas ambos abraçavam-na.

Porém, a frustração dos federalistas em relação ao governo imperial não tardou a se manifestar. Por um lado, acontecimentos ocorridos no Rio de Janeiro e sabidos em Pernambuco a 13 de dezembro de 1823, revelaram que entre as noções de federalismo constitucionalista e lealdade dinástica, o príncipe optava pela segunda. Nessa direção, fatos como o fechamento da Assembléia constituinte sob baionetas, o acirramento das ações contrárias à liberdade de imprensa - que vinham sendo tomadas desde 1822 contra o Correio do Rio de Janeiro, de João Soares Lisboa - e a carta de lei de 20 de outubro de 1823, que acabava com as Juntas e instituía a presidência da província, deixavam claro que as pretensões federalistas estavam com seus dias contados. Curiosamente, porém, acreditava-se que o príncipe mantinha seus princípios constitucionais intactos, e que seriam seus apaniguados quem trabalhavam contra a união federativa do Império. Na edição de 19 de fevereiro de 1824 do seu Typhis Pernambucano, frei Caneca ainda sustentava a idéia segundo a qual "há de raiar o dia em que o

de Janeiro. Rio de Janeiro: Typ. De G. Leuzinger \& Filhos, vol. XIII, 1890, p. 15-26.

${ }^{21}$ Cf: Ofício da Junta do Governo Provisório de Pernambuco ao imperador dom Pedro I. In: As Juntas Governativas e a Independência. (vol. 2). Rio de Janeiro: Conselho Federal de Cultura/ Arquivo Nacional, 1973, p. 694-695. Recife, 23 de novembro de 1822. 
nosso augusto imperador, rompendo a venda que o cega, dará avesso à luz da verdade, que lhe encobrem a mais insolente adulação e o desenfreado egoísmo dos áulicos”. Contra esses "áulicos”, caberia aos pernambucanos abrir os olhos do imperador, constituindo-se na "salvação dos nossos brasileiros", em "beneméritos da pátria, com um inauferível direito à sua gratidão”. ${ }^{22}$

A "pátria” de Caneca nem era, então, o lugar de nascimento de outrora, nem a "pátria do cidadão", isto é, do europeu da América, que ele defendera numa famosa dissertação escrita nos primeiros dias de 1822. Quando se refere aos pernambucanos constituírem a "salvação dos nossos brasileiros”, não está fazendo defesa de um federalismo provincial, ou pernambucano, mas de um princípio de federalização atinente a todas as províncias constitutivas da "pátria". Ao mesmo tempo, assistiu-se ao malogro definitivo do que restara da Junta dos Matutos em meados de dezembro de 1823. Esta já havia passado por situação vexatória em fevereiro daquele ano, quando um grupo de negros livres chefiados pelo governador das Armas, Pedro da Silva Pedroso, havia tomado a capital por toda uma semana. ${ }^{23}$ Os negros, larga maioria da população, haviam lembrado aos matutos que nem sempre eram confiáveis. Bem mais que no governo anterior, chefiado por Gervásio Pires, o qual resistiu às pressões das Cortes no sentido de desembarcar tropas portuguesas no Recife, os matutos cooptaram e se apoiaram nos militares "pretos" e "pardos" e lhes ofereceram, através da profissionalização das milícias Bravos da Pátria e Monta-Brechas, salários, fardamentos, armas e distinções. ${ }^{24}$ Depois disso, tiveram que se ver com a "Pedrosada”, uma rebelião de caráter racial.

\section{IV}

Em dezembro de 1823, Pernambuco achava-se a um passo da guerra civil. Como sempre, o movimento com o objetivo de destituir o que restara da Junta dos Matutos partira do norte da província. A 13 de dezembro de 1823, Francisco de Paula Cavalcanti de Albuquerque chamava o Grande Conselho - instituição de feições democráticas criada ao tempo de Gervásio Pires - para anunciar, já à falta de outros membros da Junta, que “achando-se a Província bandeada, e ame-

\footnotetext{
${ }^{22}$ Cf: MELLO, Evaldo Cabral de (org.). Frei do Amor Divino Caneca..., p. 360.

${ }^{23}$ Cf: SILVA, Luiz Geraldo. Negros patriotas..., p. 515-520.

${ }^{24}$ Cf: MELO, Antônio Joaquim de. Biografia de Gervásio Pires Ferreira. Vol. 1. Recife: Editora Universitária da UFPE, 1973, p. 59.
} 
açando uma Guerra Civil, havendo já Corpo reunido em Goiana”, entendia ser "um dever sagrado do Governo fazer cessar as calamidades públicas". Solicitava, então, “em nome do bem da humanidade e da Província, e mesmo em nome do Grande Império Brasileiro, que [os membros do Grande Conselho] os dispensassem de um Governo, em que tinham perdido toda a força moral”. ${ }^{25}$ Sabedores da carta de lei de 20 de outubro de 1823 que instituía a presidência da província, o Grande Conselho deliberou por nomear nova Junta, enquanto o imperador não informasse quem seria o primeiro presidente provincial. Naquela circunstância, a Junta dos Matutos deixava o poder nas mãos de um grupo que guardava claros traços de continuidade em relação aos que estiveram à frente da revolução contra o Reino Unido em 1817 e do movimento do qual resultara a formação da primeira Junta de Governo. Desse grupo político fazia parte o carmelita frei Joaquim do Amor Divino Caneca, o poeta e advogado mulato José da Natividade Saldanha e o comerciante de grosso trato Manoel de Carvalho Paes de Andrade - respectivamente, conselheiro, secretário e presidente da Junta Provisória.

No entanto, à crença quase ingênua de Caneca no imperador contrapunha-se o ardil deste em oferecer a presidência da província a Francisco Paes Barreto, morgado do Cabo, e a seu grupo adesista. Esta atribuição havia sido feita em 25 de novembro de 1823, mas quedara ignorada em Pernambuco até fevereiro de 1824. Na sessão do Conselho da Província do dia 3 daquele mês, discutiu-se o teor do "ofício do Morgado [Francisco Paes Barreto] participando ao Governo que havia recebido uma Carta Régia em que era nomeado Presidente do Governo da Província”. Membros do Conselho, a exemplo de Manoel Silvestre de Araújo, entenderam que não se devia dar a posse a Paes Barreto, ao passo que outros, como Bernardo Luiz Ferreira, pensavam o inverso. A decisão final foi a de que "não convinha por ora que se lhe desse posse" ${ }^{26} \mathrm{~A}$ idéia era protelar ao máximo o retorno da "açucarocracia" da Mata Sul ao poder e buscar uma saída negociada com o imperador. Os ânimos foram se acirrando ao longo da primeira metade de 1824. Em lados opostos, federalistas e centralizadores ameaçavam a paz da província. De um lado, Paes Barreto, conjuntamente com Luís Francisco de Paula, Bernardo Luís Ferreira, Francisco de Paula Cavalcanti e Albuquerque, José Carlos Mayrink e Manuel Inácio de Carvalho, constituem,

\footnotetext{
${ }^{25}$ Cf: Sessão extraordinária do Grande Conselho de 13 de dezembro de 1823. Atas do Conselho do Governo de Pernambuco (vol. I). Recife: Assembléia Legislativa do Estado de Pernambuco/ Arquivo Público Estadual João Emerenciano, 1997, p. 214-213.

${ }^{26}$ Cf: Sessão do dia 3 de fevereiro de 1824. Ibidem, p. 229.
} 
em 22 de março de 1824, um governo independente na vila do Cabo, seu reduto ao sul da província. Por sua vez, a Junta Provisória convocou importantes sessões do Grande Conselho até às vésperas da Confederação do Equador. A 7 de abril de 1824, numa dessas reuniões, votou-se sobre o reconhecimento de Paes Barreto como presidente da província. Num dos votos proferidos - o de frei Caneca - insistiu-se que aceitar a presidência do morgado era anuir às intenções anticonstitucionais do imperador e aceitar um projeto "despótico" para a nação. Argumenta o carmelita, enfim, que com "a nomeação do Paes Barreto em presidente não se pode conseguir o bem-estar dos povos desta província, e se arrisca a integridade do império”. Na sessão de 6 de maio, discutiu-se o envio de tropas ao sul da província "para fazer guerra às tropas de Francisco Paes Barreto". ${ }^{27}$

Nesse momento fecundo, cercado de temeridades, o confronto entre federalistas e centralizadores encerrava, em última análise, o conflito entre diferentes visões acerca da formação do Estado e da nação no Brasil. Não eram os destinos da província de Pernambuco ou mesmo das "Províncias do Norte" que estavam em discussão, mas o da nação. Por outras palavras, embora estas diferentes visões convivessem no mesmo contexto provincial, acenavam para as diferentes formas pelas quais então se construía o pacto entre governantes e governados no conjunto das províncias do Brasil. Com efeito, na sessão do Grande Conselho da Província, ocorrida a 6 de junho de 1824, Natividade Saldanha, secretário de governo, afirmou que o que desatinava no "projeto constitucional" então proposto pelo imperador não era a "insignificante extorsão de dinheiros" exigida pelos poderes centrais com base nas rendas provinciais, mas a ausência do estabelecimento de "poderes políticos, de assinar a cada um a sua esfera e de fixar os seus deveres e direitos; tratamos em suma da existência da Nação". Ainda conforme Saldanha, demandava-se "o direito de uma Assembléia Constituinte mesmo com as dificuldades e vicissitudes que são inevitáveis à liberdade e aos primeiros passos de uma nacionalidade nova, que reclamam paciência e proteção (...); queremos assim a verdade, o crédito, a superioridade e todo o proveito do Governo Representativo (...) Queremos a paz sim, mas no seio da honra satisfeita”. Para ele, aceitar o "pérfido projeto” constitucional era "arriscar a nossa ainda disputada Independência", era "reconhecer nossa incapacidade para nos constituirmos pelo modo competente". ${ }^{28}$

\footnotetext{
${ }^{27}$ Cf: MELLO, Evaldo Cabral de (org.). Frei do Amor Divino Caneca..., p. 538, 545.

${ }^{28}$ Cf: MELO, Antônio Joaquim de. Biografia de José da Natividade Saldanha. Recife: Tipographia
} 
A idéia segundo a qual o partido federalista de Pernambuco buscava uma via alternativa de construção do Estado e da nação toma consistência à medida que se compreende que o princípio de autogoverno provincial recebia, então, duros golpes por parte dos poderes que se faziam cada vez mais centrais. Desse modo, uma aspiração histórica das "províncias do Norte" - a autonomia provincial - acabava por configurar um projeto de Nação, o que impede de ver o federalismo pernambucano, ou quaisquer outros, como "separatista". A rigor, o que se origina no confronto entre, por um lado, o partido federalista e, por outro, o imperador e os centralizadores locais, não é a mera oposição de uma província isolada que insiste em manter seu autogoverno a despeito das medidas adotadas a partir de um centro qualquer de peregrinação. Antes, trata-se de um confronto entre dois projetos de nação para o que fora outrora o conjunto do território da América portuguesa.

É freqüente na historiografia saquarema a acusação de que as províncias do Norte tramavam insistentemente a quebra da "comunhão nacional" e que só o príncipe possuiu visão de conjunto de modo a aglutinar as partes sempre tendentes ao "separatismo": "A resolução de Dom Pedro [de permanecer no Brasil]", aduz Oliveira Lima, "fora efetivamente a salvação do Brasil unido - unido entre si quando deixasse de sê-lo a Portugal". ${ }^{29}$ Contudo, a idéia da integridade da América portuguesa, sempre presente às representações mentais dos federalistas pernambucanos, era bastante antiga. Em 1730, Sebastião da Rocha Pita referiase ao "opulento império do Brasil", o qual possuía "forma triangular". Seus limites naturais compreendiam extenso território que "principia pelas bandas do norte no imenso rio das Amazonas, e termina pela do sul no dilatadíssimo Rio da Prata”. Quase cem anos depois, frei Caneca retomava tal representação das "fronteiras naturais" no Sermão da Aclamação, proferido a 8 de dezembro de 1822. Ali, o carmelita descalço evocava a imagem da quebra dos "infames grilhões que o velho e estonteado Tejo, no seu mais exaltado orgulho, forjava ao colossal Amazonas e ao rico Prata" ${ }^{30}$ Em suma, não foram unicamente as elites do Centro-Sul, vistas com freqüência como "construtoras do Estado nacional", que pensaram o Brasil em seu conjunto e advogaram energicamente em favor de sua unidade. Tal integridade territorial, não-política, era pensada desde o século

de Manoel Figueroa Faria \& Filho, 1895, p. 41-44.

${ }^{29}$ Cf: LIMA, Manuel de Oliveira. O movimento da independência..., p. 158.

${ }^{30}$ Cf: MELLO, Evaldo Cabral de (org.). Frei do Amor Divino Caneca..., p. 104. 
XVIII. Ela foi, pois, apenas retomada pelos federalistas pernambucanos, já em termos políticos, nos anos turbulentos da independência, fosse no momento de apoiar a ascensão do imperador ao trono, fosse na ocasião de contestá-la.

Desse modo, não é correto afirmar que se nutria, na antecâmara da Confederação do Equador, sentimentos de esquartejamento do império. A idéia, pelo contrário, era a de que esse movimento estava sendo levado a efeito a partir do Sul, por um punhado de grupos instalados no Estado recém independente - estes, sim, dotados do mais devotado anseio político de caráter regional. Cipriano Barata, na edição de 18 de junho de 1823 da Sentinela da Liberdade na Guarita de Pernambuco, resumiu bem esse sentimento: "nós não temos feito este Império para meia dúzia de famílias do Rio de Janeiro, São Paulo e Minas Gerais desfrutarem (...) nós somos livres, as províncias são livres, o nosso contrato é provisório e não está concluído". ${ }^{31}$ Todos, e não apenas poucos grupos oligárquicos do Centro-Sul, deveriam desfrutar das benesses decorrentes do Estado independente. Ora, posto que se configurasse uma relação de usurpação de uns poucos em detrimento dos anseios por federalização e autonomia local, cabia esclarecer que havia condições virtuais para que identidades coletivas emergissem em contraste com a demanda pela unidade. Com efeito, em meio aos impasses que levarão à proclamação da Confederação do Equador, frei Caneca, na edição de 10 de junho de 1824 de seu Typhis Pernambucano, deixou claro que quando "aqueles sujeitos do sítio do Ipiranga (...) aclamaram a s. m. imperador constitucional, e foram imitados pelos aferventados fluminenses, Bahia podia constituir-se república; Alagoas, Pernambuco, Paraíba, Ceará e Piauí,federação; Sergipe d'El-Rei, reino; Maranhão e Pará, monarquia constitucional; Rio Grande do Sul, estado despótico”. Em meio a essas “possibilidades”, continua Caneca, “o Rio (...) aclamou s. m. imperador constitucional, e então s. m. não ficou mais do que imperador do Rio de Janeiro". Caso quisesse contar com a anuência das demais províncias, haver-se-ia de respeitar não apenas a idéia de monarquia, mas também a de "sistema constitucional”, pois, "sem uma Constituição dada pela nação, acabou-se a união; fica cada província sobre si independente e soberana, pois que a sua união foi anunciada e baseada no conjunto indissolúvel das duas condições, sistema constitucional e s. m. imperador" (grifos no original). ${ }^{32}$

\footnotetext{
${ }^{31}$ Cf: LEITE, Glacira L. Pernambuco, 1824: a Confederação do Equador. Recife: Massagana, 1989, p. 118.

${ }^{32}$ Cf: MELLO, Evaldo Cabral de (org.). Frei do Amor Divino Caneca..., pp. 464-465.
} 
Definitivamente, esta não era uma visão "provincial" ou mesmo "regional" do problema da formação do estado e da nação: contemplava-se o conjunto do que antes havia sido a América portuguesa, e era toda essa territorialidade e a forma de governo sobre ela que estavam em jogo. Ademais, observava-se que existiam identidades políticas regionais passíveis, na linha do Direito das gentes, lido por Caneca a partir de Pufendorf, de fundamentar a constituição de corpos políticos autônomos. Mas as bases de tais constatações não eram as identidades regionais em si, mas uma visão que contemplava o conjunto das províncias. Assim, a ruptura aparecia no horizonte apenas como resultado de profundas frustrações e, sobretudo, como uma ameaça. Na verdade, como sugerem alguns historiadores, a eclosão da Confederação do Equador, em julho de 1824, seria em parte, par a par de uma secessão, mera tentativa de sensibilizar o imperador no sentido de este voltar atrás na imposição do juramento à Constituição outorgada e renovar o chamado dos deputados constituintes ao Rio de Janeiro. ${ }^{33}$

Desse modo, a interpretação segundo a qual a Confederação do Equador constituiu um episódio "quixotesco" - elaborada entre as décadas de 1830 e 1840 pelo padre Lopes Gama - não é, pois, de todo destituída de sentido. Na edição de 23 de fevereiro de 1833 d'O Carapuceiro, Gama afirma nunca ter duvidado “das boas intenções dos Patriotas de 24; mas sempre chamei de desassisada aquela empresa". Diz igualmente "que não tinha por crime o que fizeram os Carvalhistas, mas sim por loucura”. ${ }^{34}$ Anos mais tarde, a 9 de janeiro de 1846, faz alusão em artigo publicado no jornal Sete de Setembro ao fato de que "em 1824, houve por aqui aquela quixotada da Confederação do Equador”, e no mesmo jornal, na edição de 16 de abril de 1846, se refere a "quixotal revolta republiqueira da Confederação do Equador”. ${ }^{35}$

Os errados cálculos políticos e militares, seu malogro repentino e a falsa expectativa de adesões fizeram da revolução de 1824 mais um movimento de grandes idéias que de grandes mudanças assentadas na realidade. Exagera, pois, pelo outro lado, Oliveira Lima quando afirma que "grande fora o perigo da

\footnotetext{
${ }^{33}$ É possível ler esse tipo de interpretação em MELLO, Evaldo Cabral de. Frei Caneca ou a outra Independência..., p. 38 e BERNARDES, Denis A. de M. Pernambuco e o Império (1822-1824): sem constituição soberana não há união. In: JANCSÓ, István (org.). Brasil: formação do Estado e da nação. São Paulo/Injuí: Hucitec/Unijuí, 2003, p. 245.

${ }^{34} \mathrm{Cf}$ : $O$ carapuceiro. Recife, $\mathrm{n}^{\circ}$ 41, 23 de fevereiro de 1833.

${ }^{35}$ Cf: QUINTAS, Amaro. O padre Lopes Gama - Um analista político do século passado. Recife: Editora Universitária da UFPE,1975, p. 76.
} 
associação republicana das províncias do Nordeste contra a solidez ainda não cimentada da era monárquica” ${ }^{36}$ Afinal, pouco havia se laborado até 1824 no sentido de as províncias do Norte, incluindo as do Extremo Norte, que também foram contatadas naquele momento, formarem efetivamente a "federação" que o movimento daquele ano propunha. Até Carvalho proclamar a Confederação por meio de manifestos, a crença dominante era numa revolução constitucional do Brasil, e não na secessão das províncias do Norte ou mesmo, e apenas, de Pernambuco. Note-se, ademais, que no Typhis Caneca imaginara a formação da federação independente das províncias do Norte como um exercício de retórica. Sua meta, afinal, consistia em conferir governabilidade federativa ao Brasil, do Amazonas ao Prata. Em julho de 1824, porém, a resistência "nacional" esboroou-se na dura realidade provincial.

\section{Referências bibliográficas}

BERBEL, Márcia Regina. A nação como artefato. Deputados do Brasil nas cortes portuguesas (1821-1822). São Paulo: Hucitec/Fapesp, 1999.

BERNARDES, Denis A. de M. Pernambuco e o Império (1822-1824): sem constituição soberana não há união. In: JANCSÓ, István (org.). Brasil: formação do Estado e da nação. São Paulo/Injuí: Hucitec/Unijuí, 2003.

BERNARDES, Denis A. M. O patriotismo constitucional: Pernambuco, 1820-1822. São Paulo/Recife: Hucitec/Fapesp/Editora da UFPE, 2006.

BERNARDES, Denis A. M. Pernambuco e sua área de influência: um território em transformação (1780-1824). In: JANCSÓ, István (org.). Independência: história e historiografia. São Paulo: Hucitec/Fapesp, 2005.

CARVALHO, MarcusJ.M.de.Cavalcantise cavalgados: a formaçãodasalianças políticas em Pernambuco, 1817-1824. Revista Brasileira de História, vol.18, nº 36, 1998.

JANCSÓ, István \& PIMENTA, João Paulo G. Peças de um mosaico (ou apontamentos para o estudo de emergência da identidade nacional brasileira). In: MOTA, Carlos G. (org.). Viagem incompleta. A experiência brasileira (1500-2000). São Paulo: Editora Senac, 2000.

LEITE, Glacira L. Pernambuco, 1824: a Confederação do Equador. Recife: Massagana,1989.

LIMA SOBRINHO, Barbosa. Pernambuco: da independência à Confederação do Equador. Recife: Prefeitura da Cidade do Recife, 1998.

\footnotetext{
${ }^{36}$ Cf: LIMA, Manuel Oliveira. O Império brasileiro (1821-1889). $3^{\mathrm{a}}$ ed. São Paulo: Melhoramentos, 1962, p. 335.
} 
LIMA, Manuel de Oliveira. O movimento da independência. São Paulo: Melhoramentos, 1922.

LIMA, Manuel Oliveira. O Império brasileiro (1821-1889). São Paulo: Melhoramentos, 1962.

LYRA, Maria de Lourdes Viana. 1998. Pátria do cidadão: a concepção de pátria/ nação em frei Caneca. Revista Brasileira de História, vol. 18, nº 36.

MELLO, Evaldo Cabral de (org.). Frei do Amor Divino Caneca. São Paulo: Editora 34, 2001.

MELLO, Evaldo Cabral de. A outra independência. O federalismo pernambucano de 1817 a 1824. São Paulo: Editora 34, 2004.

MELLO, Evaldo Cabral de. Frei Caneca ou a outra Independência. In: Caneca, frei do Amor Divino. 2001. In: MELLO, Evaldo Cabral de. (org.). Frei do Amor Divino Caneca. São Paulo: Editora 34. 2001.

MELLO, Evaldo Cabral. Rubro veio. O imaginário da restauração pernambucana. Rio de Janeiro: Topbooks, 1997.

MELO, Antônio Joaquim de. Biografia de Gervásio Pires Ferreira. Vol. 1. Recife: Editora Universitária da UFPE, 1973.

MELO, Antônio Joaquim de. Biografia de José da Natividade Saldanha. Recife: Tipographia de Manoel Figueroa Faria \& Filho, 1895.

QUINTAS, Amaro. O padre Lopes Gama - Um analista político do século passado. Recife: Editora Universitária da UFPE,1975.

SILVA, Luiz Geraldo. Negros patriotas. Raça e identidade social na formação do Estado-nação (Pernambuco, 1770-1830). In: JANCSÓ, István (org.). Brasil: formação do Estado e da nação. São Paulo/Injuí: Hucitec/Unijuí, 2003.

SILVA, Luiz Geraldo. O avesso da Independência: Pernambuco (1817-1824). In: MALERBA, Jurandir (org.). A Independência brasileira. Novas dimensões. Rio de Janeiro: Editora FGV, 2006, pp. 343-384.

SILVA, Luiz Geraldo. "Pernambucanos, sois portugueses!" Natureza e modelos políticos das revoluções de 1817 e 1824. Almanack Braziliense. São Paulo: Projeto Temático Formação do Estado e da Nação Brasileiros, v. 1, 2005, p. 67-79.

VARNHAGEN, Francisco Adolfo. História da independência do Brasil. Revista do Instituto Histórico e Geográfico Brasileiro. Rio de Janeiro: IHGB, Tomo LXXIX, 1916, [1876] (separata). 